\author{
Anna Stasienko \\ Uniwersytet Rzeszowski
}

\title{
O PARCELACJI W ROSYJSKIEJ REKLAMIE PRASOWEJ
}

Reklama jest integralną częścią życia współczesnego człowieka. Jest wszędzie: w radiu, telewizji, prasie, Internecie, na ulicy, w skrzynkach pocztowych itd. Powoduje to, że ma ona ogromny wpływ na kształtowanie obrazu rzeczywistości, życia, tworzenie stereotypów, a z drugiej strony jest odzwierciedleniem tych aspektów w danym społeczeństwie. W krajach postkomunistycznych rozwój reklamy jest ściśle powiązany ze zmianami gospodarczymi i społeczno-politycznymi. Pojawienie się reklamy w Rosji jest związane z polityką M. Gorbaczowa i jego ,pieriestrojką”. Po upadku komunizmu rozpoczyna się nowy okres w rozwoju kraju, następuje otwarcie się na zachód i przejmowanie tamtejszego stylu życia (Abramowicz 2003: 143-146; Ożóg 1995: 273-274).

Reklama to ,rodzaj komunikowania perswazyjnego obejmujący techniki i działania podejmowane w celu zwrócenia uwagi na produkt, usługę lub ideę". Cel reklamy może być realizowany w różny sposób i z wykorzystaniem różnych środków. Jednym z ważniejszych narzędzi reklamy jest język. Świadczy o tym m.in. fakt, iż twórcy tekstów reklamowych są niekiedy nazywani ,poetami współczesnej popkultury” (Шалунова 2005: 141). Język reklamy bardzo często utożsamiany jest z językiem sloganów (Bralczyk 2004: 124)². Nie bez powodu, gdyż to właśnie slogan jest jednym z najbardziej charakterystycznych składników reklamy i występuje w prawie każdej formie przekazu reklamowego (Krzanowska 2002: 113-120; 2003: 127-133; 2005: 305-310). Ponadto slogan to krótka forma wypowiedzi, która ma za zadanie przekazać informację o reklamowanym produkcie w jak najbardziej zwięzły sposób, zawiera w sobie całe przesłanie reklamy. Bardzo często wykorzystuje środki językowe, takie jak: odpowiednie, przyciągające odbiorcę słownictwo, nр.: скидка, новинка, stopień najwyższy przymiotnika, tryb rozkazujący, metafory, frazeologizmy, elipsę, homonimy, dużo określeń

\footnotetext{
${ }^{1}$ http://encyklopedia.pwn.pl/lista.php?co=reklama (dostęp: 26.05.2009).

${ }^{2}$ Bralczyk J. (2004), Język na sprzedaz, Gdańsk, s. 124; http://portalwiedzy.onet.pl/93923,,,'jezyk_reklam,haslo.html (dostęp: 16.02.2009).
} 
melioratywnych itd. Właściwie dobranym środkom językowym w reklamie prasowej towarzyszy zwykle odpowiednie tło, kolor, zamieszczone zdjęcie, a nawet sposób rozmieszczenia tekstu, czy rodzaj czcionki. Slogan jest łatwy do zapamiętania i ma wpływ na ludzkie emocje i decyzje.

Niniejszy artykuł poświęcony jest zjawisku określanemu w językoznawstwie rosyjskim terminem париелляция i jego występowaniu we współczesnej reklamie rosyjskiej³. Materiałem badawczym są reklamy pochodzące ze współczesnej prasy rosyjskiej.

Język reklamy powinien być bliski odbiorcy, tzn. być zbliżony do mowy ustnej, potocznej. Dotyczy to zarówno jego leksyki, jak również budowy składniowej. Zdania w reklamie powinny być krótkie i nieskomplikowane pod względem formalnym, ale złożone pod względem semantycznym. Jednym ze środków służących do kompresji tekstu jest parcelacja, która dzieli wypowiedzenie na mniej złożone, samodzielne komponenty (Шокина 2008: 3-6). Pozwala to skoncentrować uwagę odbiorcy na każdym elemencie komunikatu językowego. Dodatkowo kropka oznacza pauzę, która pobudza ciekawość odbiorcy. Podstawową funkcją parcelacji jest wyróżnienie określonej, najważniejszej części wypowiedzenia, czyli stworzenie nowego samodzielnego centrum rematycznego lub kilku takich centrów (Копнина 2008: 102; Сковородников 1980: 86). Wszystkie wymienione powyżej cechy parcelacji sprawiają, że jako jeden ze środków składni ekspresyjnej jest ona dość często używana w rosyjskiej reklamie prasowej.

W zebranym materiale faktograficznym zjawisko parcelacji występuje w konstrukcjach różnego typu:

1. Najczęściej pojawia się w wypowiedzeniach niewerbalnych, w których orzecznik oddzielony jest kropką od nazwy reklamowanego produktu w formie mianownika, np.: ВИТАСКИН БИОВИТАЛЬ. Сокровища красоты. (Vitaskin Biovital, Mini 12/02). Takie konstrukcje składniowe będące oznajmieniami utożsamiającymi, w których pominięty jest łącznik эmo, są szeroko rozprzestrzenione w reklamie. Podmiotem jest tu nazwa produktu, a pozostała część pełni funkcję orzecznika. Pominięcie łącznika upraszcza strukturę, sprawia, że orzekanie staje się pozaczasowe, uniwersalne oraz dodatkowo eksponuje orzecznik, który staje się najważniejszą częścią komunikatu (Ożóg 1995: 278; Kamińska-Szmaj 1996: 18; Шокина 2008: 6; Bralczyk 2004: 128). Niektórzy językoznawcy rosyjscy twierdzą, że parcelacja głównych członów zdania jest zjawiskiem bardzo rzadkim. Ich badania

${ }^{3} \mathrm{~W}$ polskiej literaturze językoznawczej brak odpowiednika rosyjskiego terminu париелляция. W niniejszym artykule będzie stosowany termin parcelacja dla określenia sposobu podziału zdania na dwie lub kilka samodzielnych fraz, które oddzielone są kropką, np.: Он [...] тоже пошел. В магазин. Сигарет купить (Шукшин). Zob. m.in.: Ярцева 1990: 369; Розенталь, Теленкова 2001: 310; Сковородников 1978(1): 118; Сковородников 1978(2): 58.

${ }^{4}$ Materiał faktograficzny pochodzi z czasopism rosyjskich z lat 2000-2009 takich jak: Дайджест недвижимости, Русский мир, Эксперт, Русский Newsweek, Лиза, Cosmopolitan, Marie Claire, Elle i in. 
dotyczą jednak literatury pięknej. W języku reklamy parcelacja podmiotu, a szczególnie orzeczenia jest dość częsta (Федорова, Замятина 2008: 5). W omawianych sloganach z parcelacją orzecznika można wyróżnić konstrukcje, w których:

a) w orzeczniku w sposób eksplicytny został nazwany typ reklamowanego produktu ${ }^{5}$, np.:

AÉRA TEINT Флюид Mam. Стойкий тональный крем. (Vichy, MC. 01/2003).

ABSOLUT RUBY RED. Водка с натуральным вкусом красного грейпфрута. (Е. 10/08).

Визибл Ризалтс. Дневной крем, совершенствующий кожу. (Visible Results, MC. 01/2003).

Sintra Jubilé. Высококачественная керамика и брилланты. (Rado, Elle 09/06).

W przytoczonych przykładach można wyodrębnić nie tylko wykładniki leksykalne określające typ produktu: orzeka się nie tylko, że dany produkt to krem na dzień, wódka czy ceramika i brylanty, ale dodatkowo podkreślona jest cecha, która wyróżnia je spośród innych towarów danej grupy.

b) w orzeczniku typ produktu wyrażony jest nie wprost, a w sposób implicytny poprzez:

- sugerowanie jego przeznaczenia, np.:

Стрепсилс. Первая помощь при боли в горле. (Strepsils, Cosm. 11/08).

Vichy. Источник здоровья кожи. (Vichy, MC 01/2003).

- wskazanie na efekt, rezultat działania produktu, np.:

Clearasil. Чистая кожа каждый день. (Clearasil, Mini 11/08).

R1. Легкость в каждом моменте жизни. (R1 - papierosy, Elle 09/06).

VІСНҮ. ЗДОРОВЬЕ ДЛЯ КОЖИ. ЗДОРОВЬЕ ДЛЯ ЖИЗНИ. (Vichy, Cosm. 11/08).

W sloganach tej grupy odbiorca domyśla się przynależności gatunkowej produktu poprzez skojarzenia i odwoływanie się do wiedzy językowej i pozajęzykowej.

c) w orzeczniku wyrażona jest jakość produktu, np.:

BMW 5 серии. Больше чем бизнес. (BMW) (Elle 09/06).

NISSAN X-TRAIL. СВЕРХСПОСОБНОСТИ. СВЕРХВОЗМОЖНОСТИ. (Nissan, News 4/09).

RUNEWSWEEK. RU. ПЕРЕЗАГРУЗКА. Удобный интерфейс. Безграничные возможнноcmu. (News 4/09).

RENAULT KOLEOS. Полный привод. Полная свобода. (Renault, E. 10/08).

${ }^{5} \mathrm{O}$ sposobach określania typu produktu w sloganie reklamowym zob. m. in.: Krzanowska 2007: 56-62. 
W pierwszej konstrukcji jakość produktu wyrażona jest konstrukcją porównawczą, a w trzech kolejnych kropką oddzielone zostały dwa jednorodne orzeczniki.

2. Nazwa produktu w formie mianownikowej jest też oddzielona kropką od reszty wypowiedzenia w konstrukcjach werbalnych. Reklamowany towar jest utożsamiany ze sprawcą pozytywnych działań lub jest nosicielem pożądanego stanu, np.:

Catsan. Запирает запах на замок. (Catsan, Cosm. 11/08).

Жидкое мыло Palmolive. Смягчает кожу, окружая Вас заботой... (Palmolive, Cosm. 11/08). Calve Легкий. Бережно взбивается, итобы быть густым, нежным и восхитительно вкуснылм. (Calve - majonez, Mini 11/08).

Jeśli z przytoczonych sloganów usuniemy kropkę wydzielającą podmiot, będą one miały to samo znaczenie, jednak utracą to, co dla języka reklamy jest bardzo istotne - ekspresyjność.

3. W konstrukcjach reklamowych dość często występuje też parcelacja drugorzędnych członów zdania. Od wypowiedzenia kropką mogą być oddzielone:

a) okoliczniki, np.:

Кожа становится абсолютно чистой. Моментально. (Garnier, Mini 11/08).

Мобильные вампиры днем спят, а по ночам говорят. Бесплатно. (Билайн, Интернет).

Купи квартиру на Юге. Геленджик. Россия. (Modus - nieruchomości, ДН 3/07).

Помада HYPERFULL om Max Factor. Восхитительный объем губ. Мгновенно. (Max Factor, Mini 12/02).

ВСЕ КРЕДИТЫ. Легко. Доступно. Выгодно. (www.credexpo.ru, ДН 3.07).

W przytoczonych sloganach szczególną uwagę odbiorcy zwraca się na to, że kosmetyki działają błyskawicznie, przez telefon można rozmawiać bezpłatnie, a największym atutem mieszkania jest to, że znajduje się w mieście Gelendzhik w Rosji. W dwóch ostatnich konstrukcjach orzeczenie jest opuszczone. Elipsa aktywizuje odbiorcę, który może wprowadzać tu dowolne elementy.

b) przydawki, np.:

Аромат, неподвластный времени. Для него... и для нее... (Essence pure, Mini 11/08).

Квартиры из первых рук. В подмосковье. (ПИК - nieruchomości, 3/07).

Oddzielona od reszty wypowiedzenia przydawka rzeczowna koncentruje uwagę na przeznaczeniu produktu - Для него... и для нее... i na atrakcyjnym położeniu mieszkań - В подмосковье. 
c) dopełnienia, np.:

Защити любимые вещии. С новой насадкой Soft Textile Protector. (Braun-żelazko, Cosm. 11/08). Пусть эти дни станут лучше. Вместе с always. (Always, Mini 11/08).

W powyższych sloganach nadawca, oddzielając kropką dopełnienia w formie narzędnika z przyimkiem $c$, szczególnie podkreśla, dzięki czemu odbiorca może osiągnąć pożądany stan rzeczy.

4. Jak już zostało powiedziane, język reklamy bywa utożsamiany z językiem sloganów, gdyż są one najczęściej używane i są najłatwiejsze do zapamiętania. Niemniej jednak, w niektórych reklamach prasowych znajdziemy dłuższe fragmenty tekstu, w których wykorzystywane są różne środki językowe, w tym również parcelacja. Oto przykłady:

Действительно. Чем больше волосы получают питания, тем красивее иявет. Нутрис питает волосы во время окрашивания. Когда волосы получают питание, они лучше удерживают и сохраняют иявет (...) (Garnier, Mini 12/02).

Новый Taft Coтрlete с тройным эффектом: мягкость кашемира, жемчужный блеск и заметный объем. Для превосходной фиксации и безупречного стиля. Весь день, в любую погоду. (Taft, Elle 09/06).

Oddzielona kropką od reszty wypowiedzenia fraza Действительно (nаprawdę) w szczególny sposób podkreśla, że prezentowane informacje o produkcie są potwierdzone naukowo lub przez konsumentów. Ostatni tekst składa się z wypowiedzeń niewerbalnych - zastosowano tu elipsę orzeczeń, których odbiorca może się domyślić i przekształcić tekst w zdanie złożone, np.: Покупайme Новый Taft Complete с тройным эффектом: мягкость кашемира, жемчужный блеск и заметный объем, если для Вас важна превосходная фиксация и безупречный стиль, которые продолжаются весь день и в любую погоду. Przekształcone zdanie jest długie i złożone, natomiast zastosowanie parcelacji wraz z elipsą sprawia, że frazy w tekście są krótkie i nieskomplikowane pod względem formalnym, ale złożone pod względem semantycznym.

Analiza materiału pokazuje, że parcelacja jest jednym ze środków składni ekspresyjnej wykorzystywanym w reklamie. Zastosowanie jej sprawia, że język reklamy jest zbliżony do mowy ustnej - zdania są krótkie i nieskomplikowane pod względem formalnym, a kropka (pauza) w nieoczekiwanym miejscu pobudza ciekawość odbiorcy komunikatu i zwraca uwagę na reklamowany produkt. W parcelat zostaje wyodrębniona informacja o typie produktu, jego przeznaczeniu, efekcie działania, wysokiej jakości, wyróżniającej go cesze, a także jego nazwa.

Niniejszy szkic jest jedynie zasygnalizowaniem zjawiska parcelacji w rosyjskiej reklamie prasowej. Jest to bardzo różnorodny środek stylistyczny, który w reklamie występuje wraz z innymi zabiegami językowymi i pozajęzykowymi. 


\section{Bibliografia}

Abramowicz Z. (2003), Reklama w Rosji. Zarys problematyki, [w:] Studia Wschodniostowiańskie, t. 3, Białystok, s. 143-150.

Bralczyk J. (2004), Język na sprzedaż, Gdańsk.

Encyklopedia PWN, http://encyklopedia.pwn.pl/lista.php?co=reklama (dostęp: 26.05.2009).

Język reklam, http://portalwiedzy.onet.pl/93923,,,,jezyk_reklam,haslo.html (dostęp: 16.02.2009).

Kamińska-Szmaj I. (1996), Slogan reklamowy - budowa składniowa, „Poradnik Językowy”, z. 4, Warszawa, s. 13-22.

Krzanowska A. (2002), Na marginesie zjawisk leksykograficznych czyli o leksemie slogan w języku polskim i rosyjskim, [w:] Świat Stowian w języku i kulturze III. Językoznawstwo, E. Komorowska, Ż. Kozicka-Borysowska (red.), Szczecin, s. 113-120.

Krzanowska A. (2003), Slogan reklamowy jako przedmiot badań lingwistycznych (przegląd literatury polsko- i rosyjskojęzycznej), [w:] Świat Słowian w języku i kulturze IV. Językoznawstwo, E. Komorowska, Ż. Kozicka-Borysowska (red.), Szczecin, s. 127-133.

Krzanowska A (2005)., Slogan reklamowy jako przyktad przekazu nie wprost (na materiale języka polskiego i rosyjskiego), [w:] Język a rzeczywistość, P. Czerwiński, H. Fontański (red.), Katowice, s. 305-310.

Krzanowska A. (2007), Slogany reklamowe z punktu widzenia kategorii semantycznej typ produktu - określenie typu produktu poprzez sugerowanie przeznaczenia, [w:] Dialog Kultur. Leksyka. Semantyka. Pragmatyka, E. Komorowska, U. Kantorczyk (red.), Szczecin-Rostock, s. 56-62.

Ożóg K. (1995), Kilka uwag o języku reklamy radiowej i telewizyjnej, ,Język Polski”, LXXV, z. 4-5, s. 273-279.

Bol'shoy entsiklopedicheskiy slovar'. Yazykoznanie, V. N. Yartseva (red.), Moskva 1990. / Большой энциклопедический словарь. Языкознание, В. Н. Ярцева (ред.), Москва 1990.

Fedorova M. A., Zamyatina S. N., Funktsii partsellirovannykh konstruktsiy v reklame, http://frgf. utmn.ru/No11/text10.htm, (3.08.2008). / Федорова М. А., Замятина С. Н., Функции париеллированных конструкций в рекламе, http://frgf.utmn.ru/No11/text10.htm, (3.08.2008).

Kopnina G. A., Partsellyatsya, http://library.krasu.ru/ft/ft/_articles/0070223.pdf, (3.08.2008). / Копнина Г. А., Париелляяиия, http://library.krasu.ru/ft/ft/_articles/0070223.pdf, (3.08.2008).

Rozental' D. E., Telenkova M. A. (2001), Slovar'-spravochnik lingvisticheskikh terminov, Moskva. / Розенталь Д. Э., Теленкова М. А. (2001), Словарь-справочник лингвистических terminov, Москва.

Shalunova M. S. (2005), Evolutsiya yazyka reklamy v Internete, konets XX - nachalo XXI v., [v:] Sovremennye voprosy obshchestvenno-rechevoy praktyki, A. A. Volkov (red.), Moskva, s. 141-149. / Шалунова М. С. (2005), Эволючия языка рекламы в Интернете, конец XX - начало ХХІ вв., [в:] Современные вопросы общественно-речевой практики, А. А. Волков (ред.), Москва, с. 141-149.

Shokina A. B., (2008), Yazykovaya kompressiya v reklamnom tekste, http://mediascope.ru/node/240 (21.05.2009). / Шокина А. Б. (2008), Языковая компрессия в рекламном тексте, http:// mediascope.ru/node/240 (21.05.2009).

Skovorodnikov A. P. (1978(1)), O sootnoshenii ponyatiy ,,partsellyatsya” $i$,, prisoyedinenie”, „Voprosy yazykoznaniya”, 1978/1, s. 118-129. / Сковородников А. П. (1978(1)), О соотношении понятий „париелляция” и ,,присоединение”, „Вопросы языкознания”, 1978/1, с. 118-129.

Skovorodnikov A. P. (1978(2)), O klassifikatsii partsellirovannykh predlozheniy $v$ sovremennom russkom literaturnom yazyke, „Filologicheskiye nauki”, 1978/2, s. 58-67. I Сковородников А. П. (1978(2)), О классификации париеллированных предложений в современном русском литературном языке, „Филологические науки”, 1978/2, с. 58-67. 
Skovorodnikov A. P. (1980), O funktsiyakh partsellyatsii v sovremennom russkom literaturnom yazyke, „Russkiy yazyk v shkole”, 1980/5, s. 86-91. / Сковородников А. П. (1980), О функииях париелляиии в современном русском литературном языке, „Русский язык в школе", 1980/5, с. 86-91.

Anna Stasienko

ON THE PARCELING IN RUSSIAN PRESS ADVERTISING

(Summary)

The article deals with the phenomenon of parceling, i.e. the division of a sentence into small parts. Parceled sentence consists of a main (basic) part and a partcellator. Different types of parceled constructions used in Russian press advertising have been discussed.

Keywords: parceling, partcellator, press advertising, Russian language, syntax

\section{O PARCELACJI W ROSYJSKIEJ REKLAMIE PRASOWEJ}

(Streszczenie)

Artykuł jest poświęcony zjawisku określanemu w językoznawstwie rosyjskim terminem париелляиия, tj. sposobowi podziału zdania na dwie lub kilka samodzielnych fraz.

Omówione zostały różnego typu konstrukcje z parcelacją w rosyjskiej reklamie prasowej.

Szkic jest wstępem do szczegółowego opisu danego zjawiska w planie konfrontatywnym rosyjsko-polskim.

Słowa kluczowe: parcelacja, parcelat, reklama prasowa, język rosyjski, składnia 